\title{
Asymptomatic malaria remains high among seasonal migrant workers depart to home from malarious areas and may cause a resurgence of malaria transmission at high lands of northwest Ethiopia: a cross-sectional study
}

Tesfaye Tilaye Tilaye ( $\nabla$ tilayebiru2020@gmail.com )

Public Health Institute https://orcid.org/0000-0003-2815-4434

Belay Tessema Tessema

Guangdong Institute of Microbiology

Keshaun Alemu Gelaye

Public Health Institute

Research

Keywords: asymptomatic malaria, departure, seasonal migrant workers

Posted Date: September 9th, 2021

DOl: https://doi.org/10.21203/rs.3.rs-871634/v1

License: (1) (i) This work is licensed under a Creative Commons Attribution 4.0 International License. Read Full License 


\section{Abstract \\ Background}

In Ethiopia, thousands of seasonal migrant workers used to travel from non-malaria or mild malaria transmission areas to malaria endemic areas for the purposes of seasonal farm activities. Most of these migrants are staying in the farm areas for land preparation, ploughing, planting, weeding and harvesting for specific period of time and back to their living areas. However, there is limited evidence how the seasonal migrant workers contribute in the transmission of malaria to new or less malaria transmission areas.

\section{Methods}

A cross sectional study was conducted at departure phase of seasonal migrant workers in Metema district from September 2018 to October 2019. A total of 1208 seasonal migrant workers were interviewed during their departure to home. Interviewed face to face interview was done using a pretested structured questionnaire. Moreover, blood samples were collected from each study participant for microscopic malaria parasite examination. The data was fitted with the logistic regression model to estimate the predictors' of malaria transmissions.

\section{Results}

At the departure to home, the prevalence of malaria among seasonal migrant workers was $17.5 \%$ (15.6$19.45 \%)$. About $71.80 \%$ (177/212) of the cases were Plasmodium falciparum, and $28.20 \%$ (35/212) Plasmodium vivax. The majority of seasonal migrant workers $(77.4 \%)$ were from rural residence and highlanders (55\%). Most (55.4\%) of the migrants were visited two and more farm sites during their stay at development corridors for harvesting activities. About 116 (54.7\%) asymptomatic malaria cases were returning to Dembiya(21.7\%), Chilaga(19.8\%) and Metema(13.2\%) districts.

\section{Conclusion}

This study focuses on the prevalence of asymptomatic malaria among seasonal migrant workers during the departure phase to home. The role of seasonal migrant workers in carrying and spreading malaria parasites, as well as challenging the country's malaria prevention and elimination efforts, could be enormous. Age, occupation, origin, the number of farm sites visited, and the frequency with which LLINs used were all associated with an increased asymptomatic malaria prevalence in the study area. Tailored interventions for seasonal migrant workers could be in place by programers, partners and implementers to enhance malaria control and elimination. 


\section{Background}

Malaria is continuing a global public health problem[1]. It is caused by Plasmodium parasites and in most cases, transmitted through the bites of female Anopheles mosquitoes. Among the 5 Plasmodium parasite species which cause malaria in humans, $P$. falciparum and $P$. vivax are widely distributed in the globe. In the WHO African region, Plasmodium falciparum is the most prevalent $[2,3]$.

Globally, between 2010 and 2018 successful decline of malaria incidence rate was documented, from 71 to 57 cases per 1000 population at risk[4]. However, after 2016 the success started slowing down and remains a major burden of disease [3]. In 2018, World Malaria Report indicated an estimation of 228 million malaria cases and 405,000 deaths globally. WHO African region shared $93 \%$ of all the cases and $94 \%$ of all deaths [5]. In Ethiopia, over $68 \%$ of the country landmass is still malarious where $60 \%$ of the population is at risk of malaria infection [6-8]. In 2016, an estimated three million new malaria cases and five thousand deaths were reported [9] which showed $50 \%$ malaria incidence and mortality decline compared to the previous years [10]. This achievement was associated with an improved coverage of LLINS, IRS, malaria diagnoses using RDT and prompt treatment using ACT and destruction of mosquito breeding sites using environmental management since 2005 up 2015 [10]. However, malaria remains among the ten top leading cause of morbidity and mortality [11, 12]. Moreover, the country has not yet established robust surveillance and health management information system to monitor mortality and incidence rates of malaria [11].

Migration to countries and within countries is usually cyclical and seasonal [13]. In Asia and Africa, people are moving from country to country or within the country for economic purpose, mostly for agricultural activities [14]. Most agricultural farms are found in high malaria transmission areas and movement from malaria free or low malaria areas to these areas put migrants at risk of malaria infection [15]. This would results resurgence of malaria, outbreaks, spread of malaria parasite and drug resistant malaria parasites and challenges of malaria prevention and elimination activities $[16,17]$. Studies revealed the risk of confirmed malaria in the high land areas was up to 7 times higher in people who had travel history to high malaria transmission areas than those who hadn't [18]. Moreover, studies were identified risk factors that increased exposure to malaria among seasonal migrants being a male [19], low education status and low knowledge of malaria prevention methods [17, 20, 21], sleeping outside the house and working at night, low treatment seeking behavior [22,23], and low access to and utilization of ITNs [24-26].

Studies have shown that population movement is closely linked to malaria spread, resurgence, and outbreaks [27-29] and countries have found migration as a key player in the reintroduction of malaria cases [30] and it has been posed challenges to the control and elimination of malaria [31, 32]. African countries were particularly affected by unrecognized migrants and unable to continue with the malaria elimination program. As a result, following the renewal of the malaria elimination paradigm in recent time, population movement has got recognition especially in countries which eliminated malaria and those which are moving to eliminate malaria and sustain malaria elimination[32]. 
In Ethiopia, most of the migration is seasonal or cyclical [25]. Seasonal migrant workers are key players either as active transmitter or passive acquirer. As active transmitters they harbor the parasite due to their low level of immunity or non-immune for malaria and at high risk to malaria infection and transmit the disease to areas of low or sporadic transmission and as passive acquirers they are exposed to the disease through movement from one environment to another [30, 33, 34]. Moreover, it has been shown that seasonal and short term migrant workers are more at risk of malaria infection and playing a central role in the malaria transmission due to traveling to endemic areas with no immunity or partial immunity[27]. Health facility based malaria studies revealed high prevalence of malaria parasite among returnees from malaria endemic areas $[8,24]$. Therefore, seasonal migrant workers can reintroduce the parasite and initiate resurgence and an outbreak of malaria when they return to their permanent living home where it might be malaria receptive [32].

The magnitude of malaria in seasonal migrant workers during harvest time and their role in malaria transmission to new or low malaria transmission areas is less known. Therefore, this study assessed asymptomatic malaria prevalence and associated risk factors among seasonal migrant workers at departure phase return to home. The outcome of this study could provide valid information and insight that will bridge the knowledge gap for programmatic improvement of malaria prevention and control in Ethiopia tailored to seasonal migrant workers in particular.

\section{Methods}

\section{Study area}

The study was conducted in Metema district of northwest Ethiopia (Figure1). It is one of the nine agricultural investment districts with a total of permanent resident populations of 154,618 [35]. The district is sharing boundaries with three districts, Quara, West Armachio and Chilga and Sudan as well. The study area is lowland with an average altitude of $750 \mathrm{~m}(500-1000 \mathrm{~m})$. The mean annual rainfall for the area ranges from about 850 to $1000 \mathrm{~mm}$. The district has 26 rural and three urban kebeles one district hospital, five health centres and 26 health posts as well as private facilities: 47 clinics, 5 medium diagnostic laboratory, 14 drug venders, 9 rural drug shops and 21 legal traditional medical sectors[36].

Metema district is one of the seven agricultural investment areas receiving an estimated 120,000 seasonal migrant workers mainly from Amhara region with various climatic zones: highland, midland and lowland. These migrants are mostly engaged in farm land preparation/ farm site clearing, farming, weeding and harvesting of Sesame, Sorghum, and Cotton products at their destination. Site clearing, farming, planting and weeding are take place from May to $2^{\text {nd }}$ week of September. Harvesting of Sesame is from end of September to December, major malaria transmission season following main rain season (June to September). Then few migrants will remain at distention from one month to six months to collect Sorghum and cotton. 


\section{Sample size, sampling and data collection}

Single population proportion was used to calculate the sample size with estimated proportion of $27.5 \%$ [37] and acceptable difference $=3 \%, a=5 \%$ (95\% confidence level), and 10\% non-response rate. Therefore, a total 1256 sample size was determined. The response rate was $96 \%$ (1208).

Participants were identified at departure just after they completed contractual agreement and left the farm sites to areas where they were stay for hours to few days until they got transport to their origin/home. Returnees were gathered in two towns, Delelo one and Delelo two, where approached to identify average flow of seasonal migrant workers to these towns and to identify time when to get majority of the study subjects. Registrations of migrants were done at the departure sites by data collectors daily and random sampling collection method was employed. Data collection at the departure helps to understand the quantity of malaria parasites to be carried by seasonal migrant workers from farm sites to their origin or living home.

Data on sociodemographic characteristics and knowledge of malaria prevention methods were collected from departure phase for malaria infection using structured questionnaire. The questionnaire comprised independent predictors such as sociodemographic characteristics (sex, age, education, occupation, religion, ethnics, and salary), residence (urban, rural), origin/ home land (highland, midland, lowland), and knowledge of malaria prevention methods. In this study, high land ("Dega") is defined as the origin or homeland of seasonal migrant workers where malaria transmission is low or free of malaria which situated between 2000 and 2500 m above sea level; midland ("Woina Dega") or highland fringes are geographic areas situated between 1500 and $2000 \mathrm{~m}$ above sea level and presented by both low and high malaria transmission; and lowland ("Kola") is presented by altitude less than $1500 \mathrm{~m}$ above sea level where malaria transmission is intense [38].

Ten data collectors were involved in the data collection from the departure. All data collectors have three to five years of experience of malaria data collection in the area. The quality of data collection was monitored daily by three supervisors and principal investigator.

\section{Microscopic blood examination}

Both thick and thin blood smears were prepared from each selected seasonal migrant worker following standard operating procedures [39]. Two drops of blood were collected on a clean microscopic slide. One drop was used to prepare a thick smear and the other was used to prepare a thin smear [40]. Finally, the slides were labelled with participant code and packed into slide porter after being air dried [41]. All slides were transported to Metema Hospital located in Gendewuha town. The thin smear on each slide was fixed with absolute methanol and both thick and thin smears were stained with $10 \%$ Giemsa for 10 minutes and examined microscopically under a light microscope for malaria parasites. Parasite results were reported based on screening of 100 microscopic fields at x100 magnification. The initial thick film was classified as negative if no parasites to be found after 500 white blood cells was counted. For quality assurance, $10 \%$ of positive slides were checked by senior laboratory technician for species 
confirmation[42]. Accordingly, the conformation of species types and positive reports were checked and there was no discrepancy between the first microscopists and the senior laboratory technician who controlled the quality.

\section{Variables of the study}

Independent variables are socioeconomic, demographic, knowledge and practice of malaria and malaria prevention methods, and environmental factors. Presence or absence of malaria parasites was dependent variable.

\section{Data processing and analysis}

Before entering the completed data, database template was prepared using software. Then the quantitative data was entered in to the database. Data quality was checked for completeness and consistency by running frequency and descriptive statistics.

After quality check, descriptive statistics was carried out to determine relative frequencies of all the survey variables using SPSS version 20. Appropriate graphs and tables were generated to show differences in the relative frequencies of various variables. Levels of association between various variables were determined by the Pearson $X^{2}$ test in situations where the expected frequencies were less than five. Where appropriate, values and confidence intervals $(\mathrm{Cl})$ for odds ratios (OR) were shown. The data was fitted with the Bivariate and multiple logistic regression logistic regression models to estimate the predictors' of malaria transmissions. Crude OR and Adjusted OR were calculated. $P$ values less than 0.05 was taken as statistically significant.

\section{Ethical considerations}

Ethical clearance was obtained from the institutional review board of University of Gondar. Then, Ethical Committee of Amhara Regional Health Bureau (ARHB) was informed to get further permission. Local administrations were also informed for permission and facilitation of the study. During data collection informed consent was sought from all the study participants and they were informed and assured that interviews and blood tests were completely voluntary, all data were confidential and that their names were linked to the data in any way. They were told that questions could be skipped or the interview could be stopped if they feel uncomfortable at any point. Participants were not compensated for their participation but those who were found positive for malaria parasite has given malaria treatment based on the national malaria guideline by health facility nearby. Care was taken not to link collected information to the respondents by name. Data and information collected or analysed was held confidential using code number for each completed questionnaire.

\section{Results}




\section{Socio-demographic characteristics of seasonal migrant workers}

A total of 1208 seasonal migrant worker were interviewed at departure sites from farm activities. Their mean age was $26.6 \pm 5.4$ and 27 median (IQR= 8). The majority $(99.4 \%)$ of the seasonal migrant farm workers were male and $53.5 \%$ were in the age range of $25-34$. Of the study subjects, $39.7 \%$ were able to read and write, $59.2 \%$ were farmers and $63.9 \%$ were not married. Dominantly, $97.9 \%$ were Amhara by ethnicity and $95.7 \%$ were Orthodox by religion (Table 1 ).

Table 1: Socio-demographic characteristics of seasonal farm workers at departure phase in Metema district, Northwest Ethiopia, November 25-December 10,2018(n=1208). 


\begin{tabular}{lc} 
Variables & Frequency (\%) \\
\hline Sex & \\
\hline Male & $1201(99.4)$ \\
\hline Female & $7(0.6)$ \\
\hline Age (in years) & \\
\hline $15-24$ & $453(37.5)$ \\
\hline $25-34$ & $646(53.5)$ \\
\hline $35+$ & $109(9.0)$ \\
\hline Education & \\
\hline Illiterate & $411(34.0)$ \\
\hline Read and write only & $479(39.7)$ \\
\hline Elementary & $110(9.1)$ \\
\hline Secondary and above & $208(17.2)$ \\
\hline Occupation & \\
\hline Farmer & $716(59.2)$ \\
\hline Daily laborer & $350(29.0)$ \\
\hline Student & $142(11.8)$ \\
\hline Marital status & \\
\hline Single & $14(1.2)$ \\
\hline Married & \\
\hline Divorced & $372(63.9)$ \\
\hline Religion & $397(32.9)$ \\
\hline Orthodox & \\
\hline Muslim & \\
\hline Others & \\
\hline Ethnicity & \\
\hline Amhara & \\
\hline Others & \\
\hline
\end{tabular}




\section{Prevalence of malaria}

The prevalence of Malaria at departure was 17.5\% (15.6-19.45\%). The relative Plasmodium species of positive cases were 71.80 \% (177/212) Plasmodium falciparum and 28.20\% (35/212) Plasmodium vivax. There was no mixed infection identified (Figure 2).

\section{Travel history}

The majority $935(77.4 \%)$ of the migrants were from rural residence. About $660(54.6 \%)$ were from highland which followed by low land 310(25.7\%) (Table 2). Most 537(44.5\%) of the migrants were visited one farm areas whereas $379(31.4 \%), 229(19.0 \%)$ and $63(5.1 \%)$ of the study subjects were visited two, three and four and above farm sites during their stay for farm activities. At departure phase, most of the migrants were staying outside the shelter from 6:00PM up to mid night, 12:00PM. Nearly all 1203(99.6\%) of study subjects have come from within the Amhara region and back to these areas (Figure 3). Of these, 604 (49.4\%) were from Central Gondar zone, followed by West Gondar 199 (16.5\%), North Gondar 193 (16.0\%), and South Gondar 149 (12.3\%). About $771(64 \%)$ of the study participants were from Dembia (23.4\%) and Chilga (19.5\%) woredas in Central Gondar zone and Metema (14.6\%) woreda in West Gondar zone and Dabat woreda (6.4\%) in North Gondar zone. Asymptomatic malaria distribution by their districts have shown most of the seasonal migrant farm workers up on return to Dembiya(46), Chilga(42), and Meteam(28) accounted for about 116 (54.7\%) (Figure 4).

The number of asymptomatic malaria cases was associated with period stayed at farm $\operatorname{sites}\left(\mathrm{X}^{2}=322.8, \mathrm{P}\right.$ value $=0.0001$ ). The majority of the seasonal migrant workers with asymptomatic malaria cases, $100(8.3 \%)$ were stayed at farm sites for two months, $31-60$ days and $88(7.3 \%)$ of the cases were stayed at farm sites for three months, 61-90 days (Table 2).

Table 2. Travel history of seasonal migrant workers at departure phase, Metema district, Northwest Ethiopia, November 25-December 10, 2018 ( $n=1208)$. 


$\begin{array}{lllll}\text { Variables } & N(\%) & \text { Asymptomatic malaria } & \text { P value } \\ & \text { Positive Negative } & & \end{array}$

\section{Residence}

\begin{tabular}{llllll} 
Rural & $935(77.4)$ & $175(14.5 \%)$ & $760(62.9 \%)$ & 3.893 & 0.048 \\
\hline Urban & $273(22.6)$ & $37(3.1 \%)$ & $236(19.5 \%)$ & &
\end{tabular}

\section{Origin/home land}

\begin{tabular}{llllll} 
High land & $660(54.6)$ & $143(11.8 \%)$ & $517(42.8 \%)$ & 24.675 & 0.0001 \\
\hline Mid land & $238(19.7)$ & $42(3.5 \%)$ & $196(16.2 \%)$ & & \\
\hline Low land & $310(25.7)$ & $27(2.2 \%)$ & $283(23.4 \%)$ & &
\end{tabular}

\section{Time stayed outside the shelter}

\begin{tabular}{llllll} 
6:00PM-8:00PM & $250(20.7 \%)$ & $59(4.9 \%)$ & $191(15.8 \%)$ & 9.63 & 0.022 \\
\hline 9:00PM-10:00PM & $465(38.5 \%)$ & $67(5.5 \%)$ & $398(32.9 \%)$ & & \\
11:00PM-12:00PM & $418(34.6 \%)$ & $74(6.1 \%)$ & $344(28.5 \%)$ & \\
$\geq 1: 00$ AM & $75(6.2 \%)$ & $12(1.0 \%)$ & $63(5.2 \%)$ &
\end{tabular}

\section{Number of farm sites visited}

\begin{tabular}{llllll}
\hline One & $537(44.5 \%)$ & $68(5.6 \%)$ & $469(38.8 \%)$ & 21.489 & 0.0001 \\
\hline Two & $379(31.4 \%)$ & $70(5.8 \%)$ & $309(25.6 \%)$ & & \\
\hline Three & $229(19.0 \%)$ & $57(4.7 \%)$ & $172(14.2 \%)$ & & \\
\hline Four and above & $63(5.1 \%)$ & $17(1.4 \%)$ & $46(3.8 \%)$ & & \\
\hline Days stayed at farm sites & & & & 322.8 & 0.0001 \\
\hline$\leq 30$ & $63(5.2 \%)$ & $6(0.5 \%)$ & $57(4.7 \%)$ & & \\
\hline $31-60$ & $733(60.7 \%)$ & $100(8.3 \%)$ & $633(52.6 \%)$ & & \\
\hline $61-90$ & $350(28.9 \%)$ & $88(7.3 \%)$ & $262(21.5 \%)$ & & \\
$\leq 91$ & $62(5.2 \%)$ & $18(1.5 \%)$ & $44(3.7 \%)$ & & \\
\hline
\end{tabular}


Practice of malaria prevention and control methods were assessed at departure. Accordingly, About $87.3 \%$ of respondents had no LLINs and only $12.7 \%$ of the seasonal migrants at departure had LLINs. Of 154 seasonal migrants, the majority (55.2\%) were using LLINs daily and 69(44\%0 were using LLINs sometimes. LLINs were used by $101(65.6 \%)$ in the last night at departure. Very few, 34(2.8\%) of the study subjects used repellents at the study site (Table 3 ).

Table 3: Practice of malaria prevention methods among seasonal migrant workers at Metema district, Northwest Ethiopia, November 25 - December 10, 2018 ( $n=1208)$.

Characteristics

Microscope test

Total (\%)

\section{Positive (\%) Negative (\%)}

\section{Ownership of LLINs}

\begin{tabular}{lcrr} 
Yes & $27(2.2 \%)$ & $127(10.5 \%)$ & $154(12.7 \%)$ \\
\hline No & $185(15.3 \%)$ & $869(72.1 \%)$ & $1054(87.3 \%)$
\end{tabular}

Frequency of using LLINs

\begin{tabular}{lccc}
\hline Daily & $5(3.2 \%)$ & $80(51.9 \%)$ & $85(55.2 \%)$ \\
\hline Sometimes & $22(14.3 \%)$ & $47(30.5 \%)$ & $69(44.8 \%)$ \\
\hline
\end{tabular}

Use of LLINs in the last night

\begin{tabular}{llll}
\hline Yes & $10(6.5 \%)$ & $91(59.1 \%)$ & $101(65.6 \%)$ \\
\hline No & $17(11.0 \%)$ & $36(23.4 \%)$ & $53(34.4 \%)$ \\
\hline
\end{tabular}

Use of repellents

\begin{tabular}{cccc} 
Yes & $6(0.5 \%)$ & $28(2.3 \%)$ & $34(2.8 \%)$ \\
\hline No & $206(17.1 \%)$ & $968(80.1 \%)$ & $1118(97.2 \%)$ \\
\hline
\end{tabular}

Wearing of long sleeve cloths

\begin{tabular}{lccc}
\hline Yes & $30(2.5 \%)$ & $168(13.9 \%)$ & $198(16.4 \%)$ \\
\hline No & $182(15.1 \%)$ & $828(68.5 \%)$ & $1010(83.6 \%)$ \\
\hline Smoking & & & \\
\hline Yes & $9(0.7 \%)$ & $66(5.5 \%)$ & $75(6.2 \%)$ \\
\hline No & $203(16.8 \%)$ & $930(77.0 \%)$ & $1133(93.7 \%)$
\end{tabular}

\section{Risk factors}


Univariate analysis indicated that age, occupation, marital status, residence, origin/home land, time to stay outside the shelter, number of farm sites visited and use of LLINs were significantly associated with malaria (Table 4).

Multivariable analysis revealed that age, occupation, origin, number of farm sites being visited and utilization of LLINs were significantly associated with the risk of malaria infection $(P<0.05)$. The prevalence of malaria was not significantly associated with education, residence, ownership of LLINs, repellent, wearing long sleeve cloths and smoking ( $P>0.05$, Table 4).

Study subjects in the age group of $25-34$ (AOR $=0.551,95 \% \mathrm{Cl} 0.378-0.804)$ were less likely to have malaria infection compared with the age group from 18-24 years. Similarly, risk of malaria infection (AOR $=0.338,95 \% \mathrm{Cl} 0.251-0.530$ ) was lower among study subjects from low land areas compared to study subjects from high land areas. Malaria prevalence was significantly higher among daily laborers (AOR $=1.497,95 \% \mathrm{Cl} 1.065-2.105)$ compared to farmers. On the other hand, seasonal migrant workers who had visited two farm areas $(A O R=1.588,95 \% \mathrm{Cl} 1.085-2.324)$, three farm sites $(A O R=2.421,95 \% \mathrm{Cl} 1.558$ 3.761), and four and more farm sites ( $A O R=3.164,95 \% \mathrm{Cl} 1.640-6.106)$ were significantly associated with malaria infection compared to migrants who visited only one farm site during their harvest time at destination. The finding had shown that as the number of visits of farm sites increased the risk of malaria infection was increased. Utilization of LLINs sometimes about seven times likely to risk migrants for asymptomatic malaria infection $(\mathrm{AOR}=6.80,95 \% \mathrm{Cl} 1.75-26.52)$ compared to migrants who used LLINs daily (Table 4).

Table 4, Predictors of asymptomatic malaria, Metema district, Northwest Ethiopia, November 25 December 10, 2018 ( $n=1208)$. 
Variables

Malaria

COR $\quad 95 \% \mathrm{Cl}$

AOR $\quad 95 \%$

cases

Yes

No

Age (in years)

$18-24$

$94 \quad 359 \quad 1$

1

25-34

$100 \quad 546 \quad 0.57$

$0.42-0.79$

0.55

$0.38-$

0.80

$35+$

$18 \quad 91$

91

0.49

$0.27-0.90$

$0.65 \quad 0.32-$

1.30

\section{Education}

No education

$\begin{array}{lll}165 & 725 & 1\end{array}$

Formal education

$\begin{array}{llll}47 & 271 & 0.97 & 0.69-1.37\end{array}$

\section{Occupation}

Farmer

Daily laborer

Student

\section{Residence}

Rural

Urban

\section{Origin/home land}

Highland

Midland

Lowland

Number of farm sites visited

One

Two

Three

$\begin{array}{lll}173 & 762 & 1 \\ 39 & 234 & 0\end{array}$

$\begin{array}{lll}120 & 594 & 1\end{array}$

$\begin{array}{llll}76 & 274 & 1.41 & 1.02-1.94\end{array}$

$\begin{array}{lll}16 & 128 & 0.88\end{array}$

$0.53-1.45$

$0.74 \quad 0.43-$

1.25
1.06-

2.10
(1)

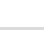


Four and above

$\begin{array}{llll}21 & 42 & 2.55 & 1.38-4.69\end{array}$

3.16

1.64-

6.11

\section{Ownership of LLINs}

\begin{tabular}{lllllll} 
Yes & 27 & 127 & 1 & & & \\
No & 185 & 869 & 1 & $0.64-1.56$ & & \\
\hline Utilization frequency of LLINs & & & & & & \\
\hline Daily & 5 & 80 & 1 & & & \\
\hline Sometimes & 22 & 47 & 7.48 & $2.66-21.09$ & 6.8 & $1.75-$ \\
\hline LLINs used in the last night & & & & & & 26.52 \\
\hline Yes & 10 & 91 & 1 & & 1 & \\
\hline No & 17 & 36 & 4.29 & $1.798-10.27$ & 1.14 & $.35-$ \\
\hline
\end{tabular}

Repellent

\begin{tabular}{lllll} 
Yes & 6 & 28 & 1 & \\
\hline No & 206 & 968 & 0.99 & $0.41-1.24$
\end{tabular}

Wearing long sleeve cloths

Yes

No

Smoking

Yes

No

\section{Yes}

es

$\begin{array}{lll}30 & 168 & 1\end{array}$

$\begin{array}{llll}182 & 828 & 1.23 & 0.81-1.87\end{array}$

9

66

$203 \quad 930 \quad 1.6$

$1.6 \quad 0.79-3.27$

1

$2.28 \quad 0.26-$

20.19

\section{Discussion}

This study characterized the role of seasonal migrant workers in carrying malaria with them while they were returning home. In this respect, asymptomatic malaria prevalence and risk factors were identified among seasonal migrant workers at departure phase. Accordingly, asymptomatic malaria prevalence was identified and multivariable logistic regression analysis revealed that age, occupation, origin, number of farm sites being visited, and utilization frequency of LLINs were significantly associated with asymptomatic malaria prevalence the risk of malaria infection. 
In this study, significant amount of asymptomatic malaria infection was identified among seasonal migrant workers at departure. The result identified that prevalence of asymptomatic malaria cases was $17.5 \%$ (Table 2) with high proportion of Plasmodium falciparum (71.8\%). It was in line with the study conducted in West Armachio district of Northwest Ethiopia and Dilla town in South Ethiopia $[43,44]$ and India [45]and lower than the study conducted in in East Shewa zone, Oromia, Ethiopia [46, 47], Nigeria[48], Tanzania[49], India [50] and China-Myanmar border, Southeast Asia [51] and higher than the study conducted in Gondar Zuria district of Northcentral Ethiopia and Democratic Republic of Congo [52, 53]. The possible reason for high prevalence of asymptomatic malaria might be due to significant proportion of seasonal migrant farm workers who had repeated malaria exposure due to frequent visit of the farm areas in the previous year or those who came from malaria endemic areas for harvesting that would facilitate to develop partial immunity and then to carry the parasite for long periods without showing clinical sign and symptoms [54-56]. Asymptomatic malaria cases might be responsible to spread malaria in areas where they are passing through while they are returning home and their communities. Study conducted in villages around Lake Tana, Northwest Ethiopia indicated that travel to farms in the lowlands was significantly associated with risk of malaria infection and imported malaria (91.5\%) to the villages[8]. Moreover, the possible reasons for the difference could be differences in study design, geographical location, nature of study population, sample size, tool used, study period and the implemented malaria control program in the study area.

In this study, age is considered one of the most important factors associated with asymptomatic malaria infection at departure [57]. Age groups from $25-34$ were protective for asymptomatic malaria infection compared with age group from 16-24. This was in agreement with the studies conducted in Ethiopia[53] and Yemen where adults were predominantly asymptomatic malaria carriers compared to children[58]. The reference age groups is more at risk of malaria infection compared to adults who are asymptomatic parasite carriers because they have acquired strong immunity from repeated exposures to malaria parasite. Moreover, high exposure at farm areas, visiting various farm sites and less use of preventive methods put this age group more at risk of malaria in the study area.

In this study occupation was significantly associated with high risk of malaria infection. Being daily laborers (individuals who work for daily wages) was at increased risk of asymptomatic malaria infection compared to farmers (persons whose farming is the main source of income). This might be due to high exposure to malaria infection that might be related to low income[59], less access to malaria information[8], behavior[43], less access to malaria prevention methods[26,60], and having no access to health care[26]. According to the study conducted in Dembiya district, Northcentral Ethiopia, low malaria information was responsible for high malaria prevalence among study subjects who had travel history to low land malarious areas[8]. However, there was no significant association of malaria prevalence with students.

This study revealed, majority of the seasonal migrants' farm workers were from rural residence of high land areas and low land areas. The risk of malaria infection is high among migrants from highland areas due to low immunity for malaria. This might be the reason for high malaria prevalence in this study

Page 15/26 
groups at departure. This was in agreement with the study conducted in West Armachiho district, Northwest Ethiopia [43]. There was evidence that travelers from high land areas to low land areas for farm activities were responsible for spread of malaria to high land areas[55].

In this study, number of farm sites being visited by study subjects was associated with risk of asymptomatic malaria at departure. It was found that as the number of farm sites being visited was increased the risk of asymptomatic malaria was increased with (Table 4). Seasonal migrant workers who had visited two, three and four and above were significantly associated with prevalence of asymptomatic malaria compared to seasonal migrant workers who had visited one farm site during their harvest time at development corridors. Visits of three and four farm sties were more than two and three times at risk of asymptomatic malaria infection compared to having one farm site visit.

In the current study, the ownership of LLINs was low among the study subjects. Only $12.7 \%$ of them possessed LLINs. LLIN ownership was lower compared with other studies in the area showing $32.4 \%$ in 2014[24], 64\% in 2015 national MIS[61], and 31\% in 2016[62]. Moreover, the ownership was also lower than the study findings from Cambodia[63]. Of the total 154 (12.7\%) seasonal migrant workers who owned LLINs, 85(55.2\%) were using LLINs daily. LLINs utilization was similar with the study conducted among seasonal migrant workers in Myanmar[64]. However, higher compared with the study conducted in Ethiopia showing 29\% in 2019[65]. The study finding also revealed that about $66 \%$ of those who owned LLINs were slept under LLINs in the previous night. This finding was higher compared with the study conducted in Myanmar showing 50\% among seasonal migrants[64]. This might be associated with low access to LLINs and most of the seasonal migrant workers did not bring their LLINs from home to farm areas.

This study kept its strength by taking an increased samples and sampling techniques to minimize selection bias and to ensure internal and external validity. Confounding factors were also contained using Binary Logistic Regression analysis. Asymptomatic malaria prevalence and associated risk factors were investigated to determine the role of seasonal migrant workers in transporting malaria parasites to their origin upon return and the risk of spreading and challenging malaria prevention and control activities as well elimination goal in the country. Failed to use molecular tool PCR in detecting asymptomatic malaria to support microscopic investigation was the limitation of this study.

\section{Conclusion}

This study highlights high asymptomatic malaria prevalence among seasonal migrant workers departure/upon return migration phase. The role of seasonal migrant workers to carry and spread malaria parasite and challenging country's malaria prevention and elimination activities could be immense. Age, occupation, origin, number of farm sites being visited, and utilization frequency of LLINs were significantly associated with an increased asymptomatic malaria prevalence in the study area. More is still needed to work on practice malaria prevention and control methods. 


\section{Declarations}

\section{Acknowledgments}

We are grateful to Ethiopian Public Health Institute for funding and our appreciation also goes to Metema district health office, data collectors and supervisors for their diligent work and study participants for their time and cooperation.

\section{Authors' contributions}

TT, KA designed the study. TT, BT, KA implemented the study. TT, KA interpreted the data. TT wrote the first draft of the manuscript. TT, BT, KA critically revised the manuscript for important content. All authors read and approved the final manuscript.

\section{Funding}

This study was funded by Public Health Emergency Management Directorate, Ethiopian Public Health Institute, Addis Ababa.

\section{Availability of data and materials}

Data and all the necessary materials are available with the corresponding author upon the request

\section{Ethical approval and consent to participants}

Ethical clearance was obtained from the institutional review board of University of Gondar. Then, Ethical Committee of Amhara Regional Health Bureau (ARHB) was approached to get further permission. Local administrations were also informed for permission and facilitation of the study. During data collection, informed consent was sought from all the study participants and they were informed and assured that interviews and blood tests were completely voluntary. Malaria cases were treated according to the national malaria guidelines.

\section{Consent for publication}

Not applicable

\section{Competing interests}

The authors declare that they have no competing interests.

\section{Author affiliations}

${ }^{1}$ Institute of Public Health , University of Gondar, ${ }^{2}$ Department of Medical Microbiology, College of Medicine and Health Sciences, University of Gondar , ${ }^{3}$ Institute of Public Health, University of Gondar, Gondar, Ethiopia. 
1tilayebiru2020@gmail.com, ${ }^{2}$ bt1488@yahoo.com, ${ }^{3}$ kassalemu@gmail.com

\section{References}

1. Girum T, Shumbej T, Shewangizaw M: Burden of malaria in Ethiopia, 2000-2016: findings from the Global Health Estimates 2016. Tropical Diseases, Travel Medicine and Vaccines 2019, 5(1):1-7.

2. Dufera M, Dabsu R, Tiruneh G: Assessment of malaria as a public health problem in and around Arjo Didhessa sugar cane plantation area, Western Ethiopia. BMC Public Health 2020, 20:1-10.

3. Organization WH: World Malaria Report 2019. 2019.

4. $\quad$ Organization WH: World Malaria Report 2018. http://appswhoint 2018.

5. Ganfon H, Ekanmian G, Amoussou L, Daniel-Garcia E, Allabi AC: Evaluation of the knowledge and attitude of pharmacists about the national malaria control policy in southern Benin. Malaria journal 2017, 16(1):231.

6. Nega D, Dana D, Tefera T, Eshetu T: Prevalence and predictors of asymptomatic malaria parasitemia among pregnant women in the rural surroundings of Arbaminch Town, South Ethiopia. PLOS One 2015, 10(4).

7. Haile M, Lemma H, Weldu Y: Population Movement as a Risk Factor for Malaria Infection in HighAltitude Villages of Tahtay-Maychew District, Tigray, Northern Ethiopia: A Case-Control Study. The American journal of tropical medicine and hygiene 2017, 97(3):726-732.

8. Malede A, Alemu K, Aemero M, Robele S, Kloos $\mathrm{H}$ : Travel to farms in the lowlands and inadequate malaria information significantly predict malaria in villages around Lake Tana, Northwest Ethiopia: a matched case-control study. Malaria journal 2018, 17(1):290.

9. Health. FDRoEMo: Ethiopian national malaria indictor survey 2011:technical summary Ethiopian:Ministry of Health of Ethiopia; 2012.

10. Yaya S, Bishwajit G, Ekholuenetale M, Shah V, Kadio B, Udenigwe O: Knowledge of prevention, cause, symptom and practices of malaria among women in Burkina Faso. PLoS One 2017, 12(7):e0180508.

11. Deribew A, Dejene T, Kebede B, Tessema GA, Melaku YA, Misganaw A, Gebre T, Hailu A, Biadgilign S, Amberbir A: Incidence, prevalence and mortality rates of malaria in Ethiopia from 1990 to 2015: analysis of the global burden of diseases 2015. Malaria Journal 2017, 16(1):1-7.

12. Girum T, Shumbej T, Shewangizaw M: Burden of malaria in Ethiopia, 2000-2016: findings from the Global Health Estimates 2016. Tropical Diseases, Travel Medicine and Vaccines 2019, 5(1):11. 
13. IOM.: A Global Report on Population Mobility and Malaria: Moving towards elimination with migration in mind. . 2013.

14. Lambin EF, Meyfroidt P: Global land use change, economic globalization, and the looming land scarcity. Proceedings of the National Academy of Sciences 2011, 108(9):3465-3472.

15. Schicker RS, Hiruy N, Melak B, Gelaye W, Bezabih B, Stephenson R, Patterson AE, Tadesse Z, Emerson PM, Richards FO, Jr. et al: A Venue-Based Survey of Malaria, Anemia and Mobility Patterns among Migrant Farm Workers in Amhara Region, Ethiopia. PLoS One 2015, 10(11):e0143829.

16. Cotter $\mathrm{C}$, Sturrock $\mathrm{H}$, Hsiang Mea: The changing epidemiology of malaria elimination: new strategies for new challenges. Lancet Infect Dis 2013, 382:900-911.

17. Tatem AJ, Jia P, Ordanovich D, Falkner M, Huang Z, Howes R, Hay SI, Gething PW, Smith DL: The geography of imported malaria to non-endemic countries: a meta-analysis of nationally reported statistics. The Lancet Infectious Diseases 2017, 17(1):98-107.

18. Lynch CA, Bruce J, Bhasin A, Roper C, Cox J, Abeku TA: Association between recent internal travel and malaria in Ugandan highland and highland fringe areas. Tropical medicine \& international health : $T M \& I H 2015,20(6): 773-780$.

19. Chaveepojnkamjorn W, Pichainarong N: Behavioral factors and malaria infection among the migrant population, Chiang Rai province. Journal of the Medical Association of Thailand = Chotmaihet thangphaet 2005, 88(9):1293-1301.

20. Phyo Than W, Oo T, Wai KT, Thi A, Owiti P, Kumar B, Deepak Shewade H, Zachariah R: Knowledge, access and utilization of bed-nets among stable and seasonal migrants in an artemisinin resistance containment area of Myanmar. Infectious diseases of poverty 2017, 6(1):138.

21. Nyunt MH, Aye KM, Kyaw MP, Kyaw TT, Hlaing T, Oo K, Zaw NN, Aye TT, San NA: Challenges in universal coverage and utilization of insecticide-treated bed nets in migrant plantation workers in Myanmar. Malaria journal 2014, 13:211.

22. Manana PN, Kuonza L, Musekiwa A, Mpangane HD, Koekemoer LL: Knowledge, attitudes and practices on malaria transmission in Mamfene, KwaZulu-Natal Province, South Africa 2015. BMC public health 2018, 18(1):41.

23. Seck MC, Thwing J, Fall FB, Gomis JF, Deme A, Ndiaye YD, Daniels R, Volkman SK, Ndiop M, Ba M: Malaria prevalence, prevention and treatment seeking practices among nomadic pastoralists in northern Senegal. Malaria journal2017, 16(1):413.

24. Alemu K, Worku A, Berhane Y, Kumie A: Spatiotemporal clusters of malaria cases at village level, northwest Ethiopia. Malaria journal 2014, 13:223. 
25. Yukich JO, Taylor C, Eisele TP, Reithinger R, Nauhassenay H, Berhane Y, Keating J: Travel history and malaria infection risk in a low-transmission setting in Ethiopia: a case control study. Malaria journal 2013, 12(1):33.

26. Schicker RS, Hiruy N, Melak B, Gelaye W, Bezabih B, Stephenson R, Patterson AE, Tadesse Z, Emerson PM, Richards Jr FO: A venue-based survey of malaria, anemia and mobility patterns among migrant farm workers in Amhara Region, Ethiopia. PLoS One 2015, 10(11):e0143829.

27. IOM.: Malaria on the Move: Mapping of Population Migration and Malaria in the South-Eastern Region of Myanmar. (Report Myanmar: International Organization for Migration and World Health Organization, Country Office) 2013.

28. Wakgari Deressa, Ahmed Ali, Berhane. Y: Review of the interplay between population dynamics andmalaria transmission in Ethiopia. . EthiopJHealth Dev 2006, 20(3):137-144.

29. Naman K Shah, Gajender P S Dhillon, Adtiya P Dash, Usha Arora, Steven R Meshnick, Valecha. N: Antimalarial drug resistance of Plasmodium falciparum in India: changes over time and space. Lancet Infect Dis 2011, 11(1):57-64.

30. Inungu JN, Ankiba N, Minelli M, Mumford V, Bolekela D, Mukoso B, Onema W, Kouton E, Raji D: Use of Insecticide-Treated Mosquito Net among Pregnant Women and Guardians of Children under Five in the Democratic Republic of the Congo. Malar Res Treat 2017, 2017:5923696.

31. Watanabe N, Kaneko A, Yamar S, Taleo G, Tanihata T, Lum JK, Larson PS, Shearer NB: A prescription for sustaining community engagement in malaria elimination on Aneityum Island, Vanuatu: an application of Health Empowerment Theory. Malaria journal 2015, 14:291.

32. Cox SN, Guidera KE, Simon MJ, Nonyane BAS, Brieger W, Bornman MS, Kruger PS: Interactive Malaria Education Intervention and Its Effect on Community Participant Knowledge: The Malaria Awareness Program in Vhembe District, Limpopo, South Africa. International quarterly of community health education 2018, 38(2):147-158.

33. Elisabeth Carmen Duarte, Theresa W Gyorkos, Lorrin pang, M. A: Epidmiology of malaria in a hypoendemic Brazilian Amazon Migrant Population:A Cohort study. AmJTrop Med Hyg, 2004, 70((3):229237.

34. Wai KT, Kyaw MP, Oo T, Zaw P, Nyunt MH, Thida M, Kyaw TT: Spatial distribution, work patterns, and perception towards malaria interventions among temporary mobile/migrant workers in artemisinin resistance containment zone. BMC Public Health 2014, 14:463.

35. Central Statistical Agency (SCA) AA, Ethiopia. : 2017.

36. Metema Health Office Md, Northwest Ethiopia. : Annual Health Report. 2017. 
37. Sahan K, Pell C, Smithuis F, Phyo AK, Maung SM, Indrasuta C, Dondorp AM, White NJ, Day NP, von Seidlein $L$ et al: Community engagement and the social context of targeted malaria treatment: a qualitative study in Kayin (Karen) State, Myanmar. Malaria journal 2017, 16(1):75.

38. Animut A, Lindtjørn B: Use of epidemiological and entomological tools in the control and elimination of malaria in Ethiopia. Malaria journal 2018, 17(1):26.

39. World Health Organization: Basic Malaria Microscopy. Part I:. Learner's guide Geneva, Switzerland:World Health Organization 1991.

40. Cheesbrougu M: District Laboratory Practice in Tropical Countries, 2nd edition Cambridge University Press 2006:319-329.

41. Nyirakanani C, Chibvongodze R, Habtu M, Masika M, Mukoko D, Njunwa KJ: Prevalence and risk factors of asymptomatic malaria among underfive children in Huye District, Southern Rwanda. Tanzania Journal of Health Research 2018, 20(1).

42. Berzosa P, de Lucio A, Romay-Barja M, Herrador Z, González V, García L, Fernández-Martínez A, Santana-Morales M, Ncogo P, Valladares B: Comparison of three diagnostic methods (microscopy, RDT, and PCR) for the detection of malaria parasites in representative samples from Equatorial Guinea. Malaria journal 2018, 17(1):333.

43. Aschale Y, Mengist A, Bitew A, Kassie B, Talie A: Prevalence of malaria and associated risk factors among asymptomatic migrant laborers in West Armachiho District, Northwest Ethiopia. Research and Reports in Tropical Medicine 2018, 9:95.

44. Molla E, Ayele B: Prevalence of malaria and associated factors in Dilla town and the surrounding rural areas, Gedeo Zone, Southern Ethiopia. Journal of Bacteriology \& Parasitology 2015, 6(5):1.

45. Kumari P, Sinha S, Gahtori R, Yadav CP, Pradhan MM, Rahi M, Pande V, Anvikar AR: Prevalence of Asymptomatic Malaria Parasitemia in Odisha, India: A Challenge to Malaria Elimination. The American Journal of Tropical Medicine and Hygiene 2020, 103(4):1510-1516.

46. Midega JT, Smith DL, Olotu A, Mwangangi JM, Nzovu JG, Wambua J, Nyangweso G, Mbogo CM, Christophides GK, Marsh K: Wind direction and proximity to larval sites determines malaria risk in Kilifi District in Kenya. Nature communications 2012, 3(1):1-8.

47. Tadesse F, Fogarty AW, Deressa W: Prevalence and associated risk factors of malaria among adults in East Shewa Zone of Oromia Regional State, Ethiopia: a cross-sectional study. BMC public health 2018, 18(1):25.

48. Fana SA, Bunza MDA, Anka SA, Imam AU, Nataala SU: Prevalence and risk factors associated with malaria infection among pregnant women in a semi-urban community of north-western Nigeria. Infectious diseases of poverty 2015, 4(1):1-5. 
49. Sumari D, Mwingira F, Selemani M, Mugasa J, Mugittu K, Gwakisa P: Malaria prevalence in asymptomatic and symptomatic children in Kiwangwa, Bagamoyo district, Tanzania. Malaria journal 2017, 16(1):1-7.

50. Chourasia M, Raghavendra K, Bhatt R, Swain D, Valecha N, Kleinschmidt I: Burden of asymptomatic malaria among a tribal population in a forested village of central India: a hidden challenge for malaria control in India. Public Health 2017, 147:92-97.

51. Z Zhao Y, Zeng J, Zhao Y, Liu Q, He Y, Zhang J, Yang Z, Fan Q, Wang Q, Cui L: Risk factors for asymptomatic malaria infections from seasonal cross-sectional surveys along the China-Myanmar border. Malaria journal 2018, 17(1):247.

52. Bahati YL, Delanghe J, Balaluka GB, Kishabongo AS, Philippe J: Asymptomatic Submicroscopic Plasmodium Infection Is Highly Prevalent and Is Associated with Anemia in Children Younger than $\mathbf{5}$ Years in South Kivu/Democratic Republic of Congo. The American Journal of Tropical Medicine and Hygiene 2020, 102(5):1048-1055.

53. Minwuyelet A, Eshetu T, Milikit D, Aschale Y: Prevalence and Risk Factors of Asymptomatic Plasmodium Infection in Gondar Zuria District, Northwest Ethiopia. Infection and Drug Resistance 2020, 13:3969.

54. Doolan DL, Dobaño C, Baird JK: Acquired immunity to malaria. Clinical microbiology reviews 2009, 22(1):13-36.

55. Alemu K, Worku A, Berhane Y, Kumie A: Men traveling away from home are more likely to bring malaria into high altitude villages, northwest Ethiopia. PLoS One 2014, 9(4):e95341.

56. Gryseels C, Grietens KP, Dierickx S, Xuan XN, Uk S, Bannister-Tyrrell M, Trienekens S, Ribera JM, Hausmann-Muela S, Gerrets R: High mobility and low use of malaria preventive measures among the Jarai male youth along the Cambodia-Vietnam border. The American journal of tropical medicine and hygiene 2015, 93(4):810-818.

57. Graves PM, Richards FO, Ngondi J, Emerson PM, Shargie EB, Endeshaw T, Ceccato P, Ejigsemahu Y, Mosher AW, Hailemariam A: Individual, household and environmental risk factors for malaria infection in Amhara, Oromia and SNNP regions of Ethiopia. Transactions of the Royal Society of Tropical Medicine and Hygiene 2009, 103(12):1211-1220.

58. Bamaga OA, Mahdy MA, Mahmud R, Lim YA: Malaria in Hadhramout, a southeast province of Yemen: prevalence, risk factors, knowledge, attitude and practices (KAPs). Parasites \& vectors 2014, $7(1): 351$.

59. Essendi WM, Vardo-Zalik AM, Lo E, Machani MG, Zhou G, Githeko AK, Yan G, Afrane YA: Epidemiological risk factors for clinical malaria infection in the highlands of Western Kenya. Malaria 
journal 2019, 18(1):1-7.

60. Chen I, Thanh HNT, Lover A, Thao PT, Luu TV, Thang HN, Thang ND, Neukom J, Bennett A: Malaria risk factors and care-seeking behaviour within the private sector among high-risk populations in Vietnam: a qualitative study. Malaria journal 2017, 16(1):1-14.

61. Institute. EPH: Ethiopia National Malaria Indicator Survey 2015. Addis Ababa, Ethiopia: Ethiopian Public Health Institute. 2016.

62. Deressa W: Individual and household factors associated with ownership of long-lasting insecticidal nets and malaria infection in south-central Ethiopia: a case-control study. Malaria journal 2017, 16(1):402.

63. Kheang ST AP, Emma LC, et al., : A Cross-sectional survey of knowledge of malaria prevention among mobile and migrant populations in Cambodia. Peeventive Medicine and Community Health 2019.

64. Than WP, Oo T, Wai KT, Thi A, Owiti P, Kumar B, Shewade HD, Zachariah R: Knowledge, access and utilization of bed-nets among stable and seasonal migrants in an artemisinin resistance containment area of Myanmar. Infectious diseases of poverty 2017, 6(1):138.

65. Birhane KG FKaWT: Assessment of Knowledge, Attitude and Practice on Insecticide Treated Net Utilization towards Malaria Prevention among Ethiopian Army members of 24th Division, 2016.Int Jof Environ Sci Nat Res 2019, 21(3)(556061.DOI: 10.19080/IJESNR.2019.21.55606).

\section{Figures}




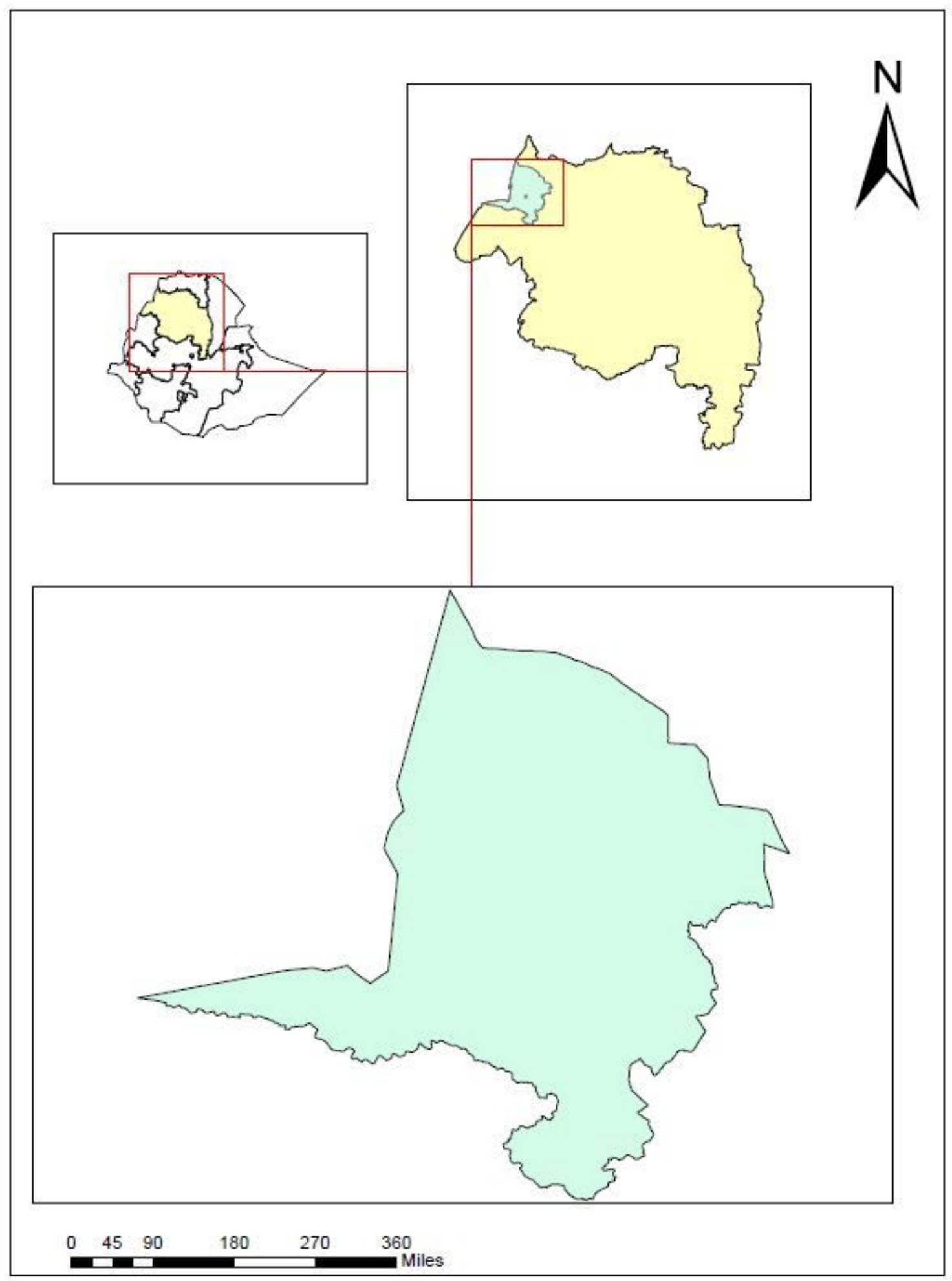

Figure 1

Map of Metema district, Northwest Ethiopia 


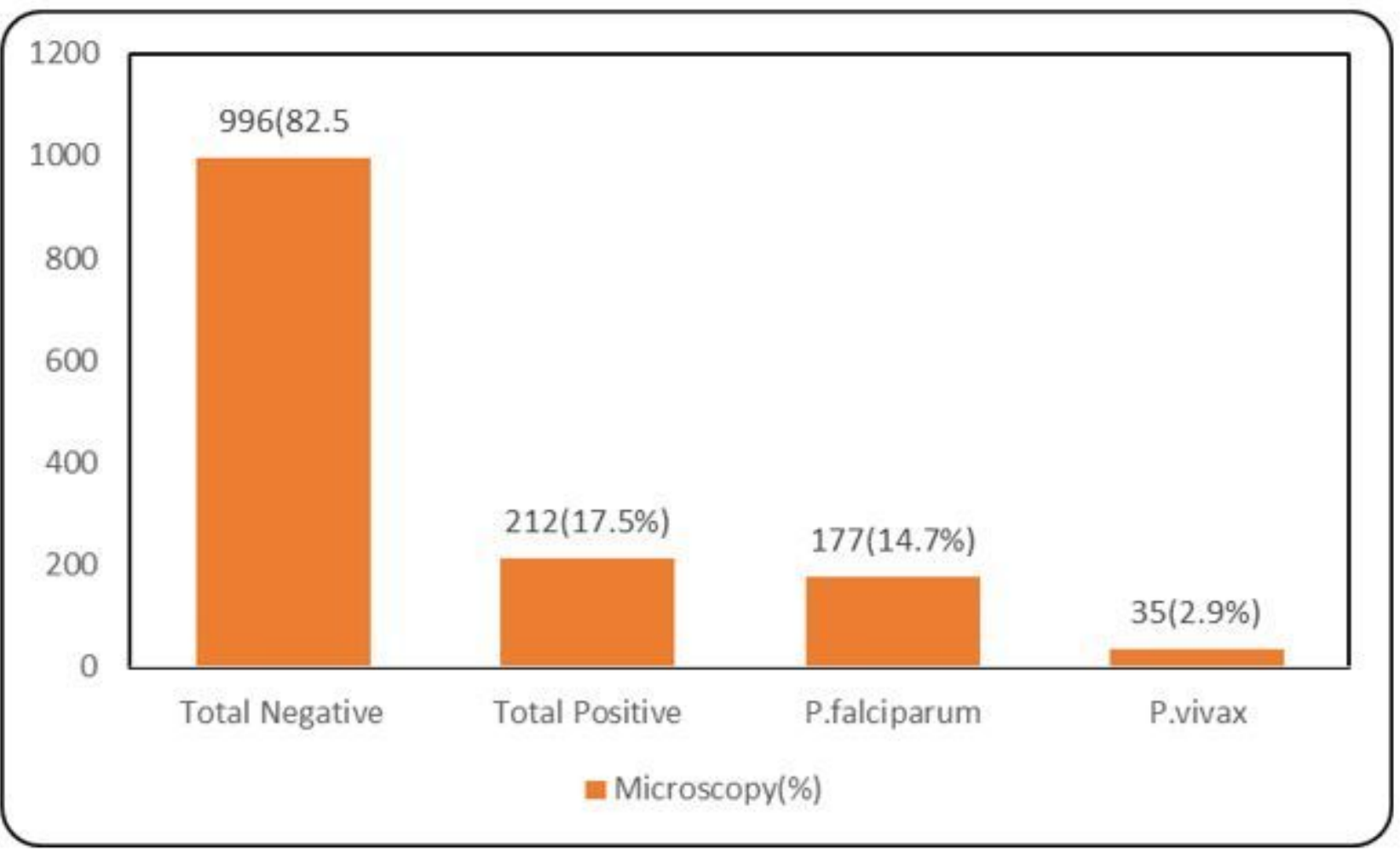

Figure 2

Malaria prevalence among seasonal farm workers at departure phase in the Metema district, Northwest Ethiopia, November 25-December 10, 2018

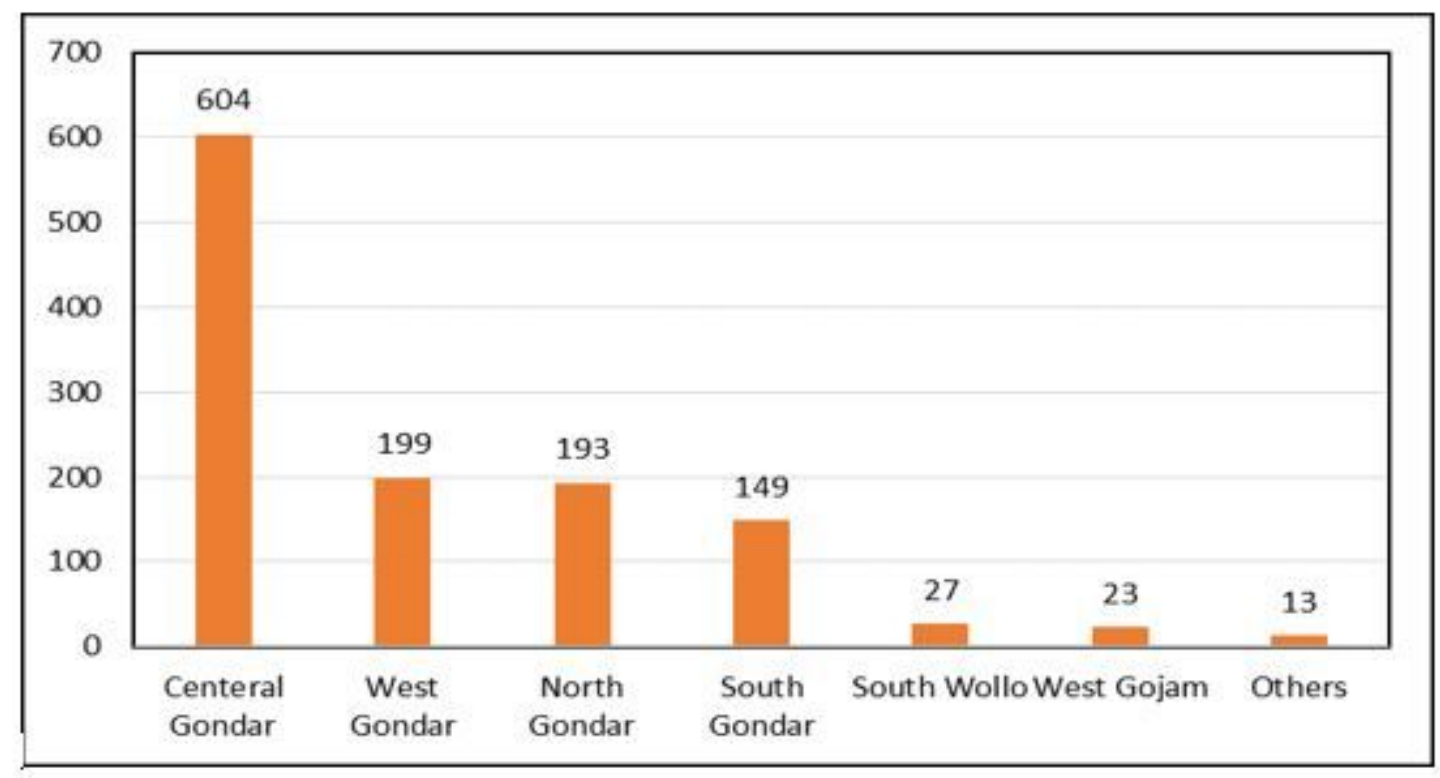

Figure 3

Study participants distribution by zones, Metema district, Northwest Ethiopia 


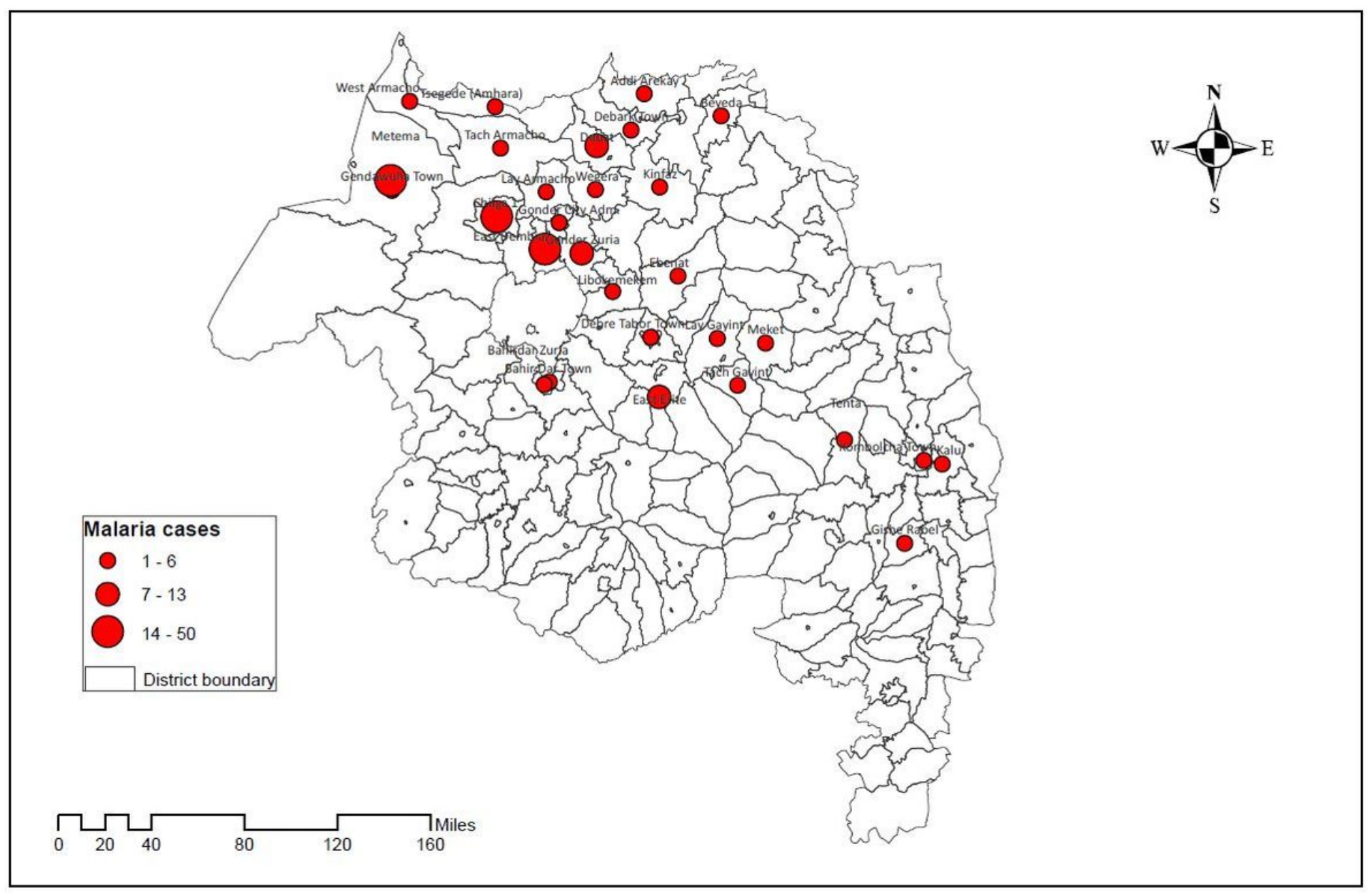

Figure 4

Asymptomatic malaria case distribution by origin/district, Metema district, Northwest Ethiopia 